\title{
AVALIAÇÃO DA EFICÁCIA DE UM PROGRAMA DE COMPREENSÃO DA LEITURA ORAL DIALÓGICA POR CRIANÇA COM AUTISMO'
}

\author{
EVALUATION OF THE EFFICACY OF A DIALOGIC READING ORAL \\ COMPREHENSION PROGRAM ON A CHILD WITH AUTISM
EVALUACIÓN DE LA EFICACIA DE UM PROGRAMA DE COMPREENSION DE LECTURA ORAL DIALOGICA EN UN NIÑO CON AUTISMO

\author{
Elizabeth Cynthia Walter ${ }^{2}$, Débora Regina de Paula Nunes ${ }^{3}$
}

\begin{abstract}
RESUMO
Os prejuízos nos níveis de compreensão leitora de educandos diagnosticados com Transtorno do Espectro Autista (TEA) aparecem documentados em pesquisas científicas. Nesse cenário, o desenvolvimento de programas de intervenção que possam remediar, precocemente, esses déficits são essenciais. 0 presente estudo tem como objetivo avaliar a eficácia de uma adaptação do programa de intervenção leitora, denominado Reading to Engage Children with Autism in Language and Learning (RECALL). Esse programa incorpora práticas interventivas, baseadas em evidências empíricas, a um modelo de Leitura Dialógica. No caso, uma mãe foi capacitada a empregar estratégias do programa, durante rotinas de leitura com o seu filho, de seis anos, diagnosticado com TEA. Por meio de um delineamento de pesquisa quase-experimental intrassujeitos, os efeitos das práticas do RECALL, implementadas pela mãe, foram avaliados quanto ao nível de responsividade de seu filho. Os resultados evidenciaram a incorporação parcial das estratégias no repertório de comportamento da mãe e aumento na frequência de ocorrência de turnos comunicativos da criança. Ganhos qualitativos foram identificados no comportamento da díade, incluindo-se melhorias nos níveis de compreensão leitora do menino. Contribuições e limitações do estudo são colocadas em discussão.
\end{abstract}

PALAVRAS-CHAVE: Autismo. Compreensão oral da leitura. Intervenção precoce. Família.

\begin{abstract}
Reading comprehension deficits in students with Autism Spectrum Disorders (ASD) are highly documented in scientific research. Thus, the development of early intervention programs that can remediate these difficulties, are essential. The present study aims to evaluate the efficacy of an adapted reading intervention program called Reading to Engage Children with Autism in Language and Learning (RECALL). This program incorporates evidence-based practices to a Dialogical Reading model. In this case, the mother was trained on how to use the program strategies during reading routines with her six-year-old son, who is diagnosed with TEA. The effects of the RECALL practice implemented by the mother were evaluated in relation to her son's level of responsiveness, using a single-subject quasi-experimental design. Results showed partial assimilation of the program strategies by the mother and an increase of frequency of the child's responses and initiations. Qualitative gains were identified in the dyad behavior, including improvements in the child's reading comprehension. Advantages and limitations of the program are discussed.
\end{abstract}

KEYWORDS: Autism. Oral Reading Comprehension. Early Intervention. Family.

\footnotetext{
1 O presente trabalho contempla dados da dissertação de mestrado da primeira autora.

2 Doutoranda em Educação - Universidade Federal do Rio Grande do Norte (UFRN) - Natal, RN - Brasil.

E-mail: elitany@gmail.com.

3 Doutora em Educação Especial - Florida State University (FSU) - Flórida - Estados Unidos. Docente Universidade Federal do Rio Grande do Norte (UFRN) - Natal, RN - Brasil. E-mail: deborareginanunes@yahoo.com.
}

Submetido em: 28/05/2019 - Aceito em: 26/08/2019

(C) ETD- Educação Temática Digital Campinas, SP $\quad$ v.22 n.1 $\quad$ p.27-49 jan./mar.2020 


\section{RESUMEN}

Las dificultades de comprensión lectora que los alumnos con diagnóstico de Trastorno del Espectro Autista (TEA) presentan, aparecen documentadas en investigaciones científicas. Frente a ese escenario, el desarrollo de programas de intervención que puedan remediar tempranamente esos déficits, es fundamental. El objetivo del presente estudio es evaluar la eficacia de la adaptación de un programa de intervención lectora, denominado Reading to Engage Children with Autism in Language and Learning (RECALL). Ese programa incorpora prácticas de intervención basadas en evidencia empírica a un modelo de Lectura Dialógica. En éste caso, una madre fue capacitada a emplear estrategias del programa durante las rutinas de lectura con su hijo de seis años, diagnosticado con TEA. Los efectos de las practicas del RECALL implementadas por la madre, en relación al nivel de responsividad de su hijo, fueron evaluados por medio de un diseño de investigación de tipo cuasi-experimental intra-sujeto. Los resultados evidenciaron la incorporación parcial de las estrategias en el repertorio de comportamiento de la cuidadora y el aumento de la frecuencia de los turnos conversacionales del niño. Avances cualitativos fueron identificados en el comportamiento del dúo, incluyendo mejoras en los niveles de comprensión lectora del niño. Contribuciones e limitaciones son discutidas.

PALABRAS-CLAVE: Autismo. Comprensión oral de la lectura. Atención temprana. Familia.

\section{INTRODUÇÃO}

O Modelo Simples de Leitura (GOUGH E TUNMER, 1986), preconiza que a compreensão leitora é ancorada em duas habilidades basilares, a de decodificar palavras escritas e a de compreender a linguagem oral. A complexa relação entre o desempenho na leitura e o desenvolvimento da linguagem é evidenciada em estudos que revelam a prevalência de déficits na compreensão leitora de populações com distúrbios de linguagem (LUCAS \& NORBURY, 2015; DAVIDSON, KAUSSHANSKAYA, WEISMER, 2018), assim como aquelas que possuem Transtorno do Espectro do Autismo (TEA).

Uma parcela significativa de pessoas com TEA não desenvolve ou não compreende, para fins comunicativos, a linguagem oral (NATION et al., 2006). A literatura registra, ainda, prejuízos nas habilidades fonológicas e semânticas desses indivíduos (EIGSTI et al., 2011; AMBRIDGE, BANNARD, JACKSON, 2015). Esses déficits, associados às dificuldades em derivar significado do contexto, reduzem a capacidade que esses indivíduos possuem em relação ao aprendizado de novas palavras (WRIGHT, PRING, EBBELS, 2018). Ademais, a compreensão leitora é afetada pela dificuldade de integrar informações textuais, assim como de fazer inferências (GANZ; FLORES, 2009), interferindo, de forma direta, na capacidade de produzir e compreender narrativas orais e escritas.

A Leitura Compartilhada (LC) é uma estratégia interventiva que tem produzido efeitos promissores, nas últimas décadas, no que se refere ao desenvolvimento da linguagem e da leitura de crianças com desenvolvimento típico (NATIONAL EARLY LITERACY PANEL [NELP], 2008), assim como, aquelas com deficiência (KADERAVEK, J., PENTIMONTI, J., \& JUSTICE, L., 2013). Dentre as modalidades de LC merece destaque a Leitura Dialógica (LD; WHITEHURST et al., 1988), um protocolo de ensino que incita a intercalação da leitura de histórias com perguntas e comentários dirigidos à criança. De forma específica, esse modelo interventivo propõe que o mediador formule, durante a leitura repetida de um mesmo livro, cinco modalidades de perguntas representadas pelo acrônimo CROWD. A letra C (complete) indica

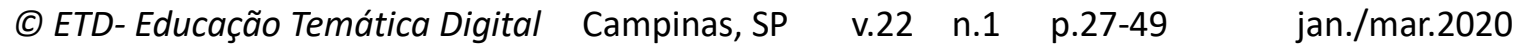


que a criança deva completar oralmente uma sentença verbalizada pelo mediador (ex: o caçador abriu a porta e viu a ...). A letra $\mathrm{R}$ (recall) diz respeito às perguntas que estimulam a rememoração de fragmentos do texto com vistas a favorecer a compreensão do enredo. $A$ vogal O (open-ended), lembra ao mediador formular perguntas abertas, como o que está acontecendo aqui? que objetivam expandir o vocabulário da criança e incitar respostas espontâneas. O W (wh-questions), que traz a mesma função, se refere a uma série de perguntas fechadas, que permitem um número limitado de respostas, como Quem? Quando? Onde? e $O$ quê?. A consoante D (distancing), por sua vez, diz respeito ao distanciamento, que tem como meta estimular a criança a relatar uma experiência pessoal, análoga à narrativa. Essa estratégia é empregada para aprimorar a capacidade de inferências extratextuais. Por fim, o mediador é orientado a estimular a participação da criança por meio de elogios e perguntas que visam a expansão de respostas.

Adicionalmente, o protocolo da LD prevê o uso do PEER, um conjunto de quatro comportamentos mediadores, que devem ser adotados pelo leitor, durante a contação da história. Nesse sentido, o $\mathrm{P}$ (prompt) diz respeito às dicas que devem ser fornecidas à criança para que ela fale sobre o livro. O E (evaluate) alerta ao mediador que avalie a pertinência e complexidade da resposta dada pela criança. Com base nessa avaliação, emprega-se o $\mathrm{E}$ (expand), que trata da expansão de respostas. Ou seja, ocorre a incitação dirigida ao mediador para este adicionar novas informações às respostas apropriadas da criança ou um modelo correto, no caso de resposta incoerente. Após a expansão, entra em cena o R (repeat) que lembra ao mediador para solicitar que a criança repita a resposta correta.

A despeito dos efeitos promissores da LD em populações com desenvolvimento típico, a dinâmica dessa modalidade interventiva não se adéqua ao perfil de alguns indivíduos com TEA. Em outras palavras, essa prática requer que a criança mantenha a atenção no adulto e na história, respondendo questões elaboradas pelo leitor, tecendo comentários e formulando novas perguntas. Tendo em vista os déficits sociocomunicativos de pessoas com TEA, é compreensivo que muitos indivíduos, com esse diagnóstico, precisem de adaptações para se engajar em atividades dessa natureza (FLEURY, et al., 2014; FLEURY; SCHWARTZ, 2016).

É nesse panorama que diversos estudos têm registrado adaptações da LD para atender às demandas dessa população (FLEURY, et al., 2014; FLEURY; SCHWARTZ, 2016; GUEVARA, QUEIROZ, FLORES, 2017; QUEIROZ, 2017; MC KENZIE, 2018). Dentre esses estudos, destacam-se aqueles que empregaram o RECALL (Reading to Engage Children with Autism in Language and Learning), um protocolo de ensino, baseado na LD, que emprega, além do PEEP e CROWD, o uso de três estratégias interventivas, a atenção compartilhada, a pausa intencional e os recursos visuais. A primeira diz respeito a um conjunto de comentários, referentes às imagens do livro, tecidos pelo mediador durante a contação da história. A segunda se caracteriza pela interrupção abrupta da leitura com vistas a eliciar uma iniciativa de resposta comunicativa da criança. A terceira estratégia incorpora recursos

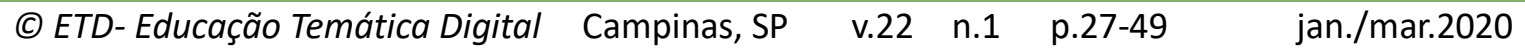


visuais em formato de livretos, contendo respostas possíveis às perguntas formuladas pelo mediador. Esse material é usado de forma estruturada, de acordo com o tipo de resposta dada pela criança.

Whalon e colaboradores (2015) e Whalon, Hanline e Davis (2016) avaliaram os efeitos do RECALL na compreensão da leitura oral e iniciativas de respostas de crianças préescolares com TEA. Os resultados revelaram aumento no número de acertos às perguntas factuais e de inferências dos participantes. Ademais, algumas crianças ampliaram a frequência de iniciativas verbais (comentários espontâneos acerca da história lida). Com base nessas pesquisas, McKenzie (2018) capacitou quatro cuidadores a utilizar o RECALL com seus filhos com TEA, que apresentavam fala funcional. Os resultados indicaram melhorias no nível de reciprocidade social das crianças.

No Brasil, Guevara, Queiroz e Flores (2017) e Queiroz (2017) avaliaram a eficácia de uma versão modificada do RECALL (Whalon et al. 2015) na comunicação de pré-escolares com TEA. No primeiro estudo, os pesquisadores observaram diminuição na frequência de comportamentos inapropriados, assim como aumento no número de respostas vocais eliciadas e independentes. De forma semelhante, o participante da segunda investigação apresentou melhorias na frequência de turnos comunicativos e respostas corretas.

Os resultados dos estudos supracitados sugerem que a leitura dialógica adaptada seja uma escolha interventiva promissora para favorecer a reciprocidade social, os turnos comunicativos e a compreensão da leitura oral de crianças com TEA. Em virtude do escasso número de pesquisas publicadas na literatura sobre esse protocolo de ensino, o objetivo geral do presente estudo é ampliar os achados de Guevara et al. (2017) e Queiroz (2017), avaliando os efeitos da leitura dialógica adaptada do RECALL, na compreensão oral da leitura de uma criança com TEA. Para operacionalizar esse objetivo, essa investigação visa (1) avaliar os efeitos de um programa de capacitação no uso de estratégias adaptadas do RECALL por um leitor e, em seguida, (2) avaliar as estratégias empregadas pelo leitor, nas respostas da criança com TEA.

\section{MÉTODO}

\subsection{Participantes}

Participaram do estudo Diego (seis anos) e sua mãe (39 anos). O menino, diagnosticado com autismo moderado pelo Childhood Autism Rating Scale (CARS, SCHOPLER, REICHLER, RENNER, 1988, traduzida por PEREIRA et al., 2008), frequentava uma creche regular no período em que o estudo foi realizado. Ele fazia sessões de fonoaudiologia, terapia ocupacional e musicoterapia desde os três anos, uma vez por semana. A mãe, que havia deixado de trabalhar após o diagnóstico do filho, tinha nível superior completo.

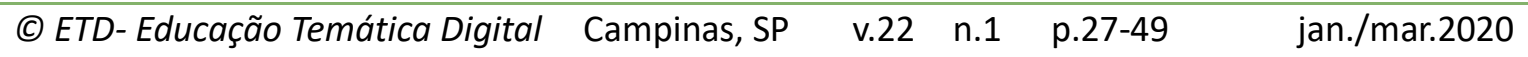


Diego havia recebido diagnóstico de TEA, por um psiquiatra infantil, aos três anos de idade. Nessa época, verbalizava palavras soltas e apresentava comportamentos ritualísticos. No período da intervenção, falava frases curtas, pouco elaboradas, empregadas primordialmente de forma protoimperativa. Suas alterações sociocomunicativas eram evidenciadas pelo precário contato ocular e os episódios de ecolalia tardia e imediata. Seu padrão de comportamento era caracterizado pela presença de estereotipias motoras, seletividade alimentar, caminhar na ponta dos pés, agitação motora e a constante busca por estímulos para "pressionar" o corpo.

\subsection{Agentes de intervenção e assistentes de pesquisa}

A primeira autora, graduada em Fonoaudiologia, atuou como agente de intervenção. Três graduandas do curso de Pedagogia trabalharam como assistentes de pesquisa.

\subsection{Local}

As sessões experimentais da pesquisa foram realizadas na residência da díade, alocada em um bairro de classe média em uma cidade do Rio Grande do Norte. As sessões de capacitação foram conduzidas num consultório. Adicionalmente, foram realizadas orientações à distância, por meio do $\mathrm{Skype}^{\circledR}$, um aplicativo digital que permite a comunicação por meio da internet.

\subsection{Materiais}

Uma filmadora digital, uma filmadora de celular, 15 livros $^{4}$ de histórias infantis. Para os seis livros usados na fase interventiva foram produzidos 12 livretos com recursos visuais (dois para cada livro, sendo um para cada dia de leitura), contendo cinco tipos de perguntas, descritas no quadro 1. Esses livretos, feitos de papel, tinham suas folhas laminadas e unidas por meio de uma argola metálica. Foram utilizados desenhos em preto e branco do site Portal Aragonés de la Comunicación Aumentativa y Alternativa (ARASAAC), também laminados, que eram anexados, com velcro, conforme ilustrado na figura 1.

Figura 1 - Livretos com dicas visuais utilizado no programa

4 Os títulos das obras estão disponíveis em Autor, 2017

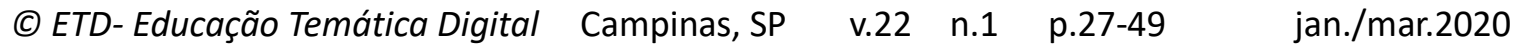




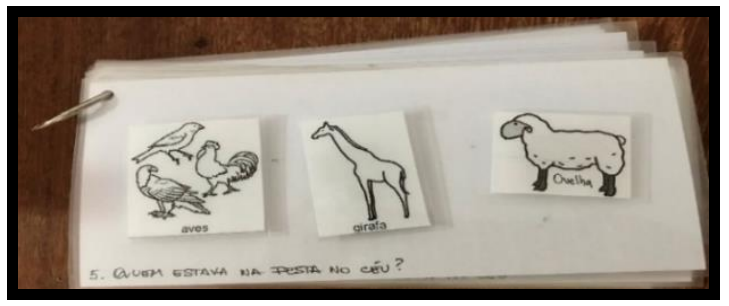

Fonte: as autoras

\subsection{Instrumentos}

Quatro instrumentos de pesquisa foram utilizados na fase inicial do estudo. $O$ primeiro, um roteiro de entrevista semi-estruturado, era composto por 10 perguntas, que versavam sobre o desenvolvimento da criança nas diferentes áreas do desenvolvimento. $O$ segundo foi o CARS (SCHOPLER et al. 1988, traduzida por PEREIRA et al., 2008), uma escala que avalia o grau de severidade de autismo. A Escala de Letramento Emergente (SAINTLAURENT, GIASSON E COUTURE, 1998, adaptada por FERNANDES, 2002), que caracteriza as habilidades de letramento emergente da criança foi o terceiro instrumento. Por fim, a quarta escala foi o Perfil de Letramento Emergente no Lar de Crianças com Transtorno do Espectro Autista (TEA) - (Home Emergent Literacy Profile for Children with Autism Spectrum Disorders; HELPA, Lanter, 2008). Traduzido e adaptado pela primeira autora, o HELPA é uma escala que avalia, de forma indireta, as habilidades emergentes da leitura e escrita e o ambiente de leitura.

\subsection{Delineamento de pesquisa}

Trata-se de uma pesquisa quase experimental de sujeito único com um delineamento do tipo A-B- Follow-up (SAMPAIO et al., 2008).

\subsection{Variáveis}

O primeiro objetivo do estudo foi avaliar os efeitos do programa de capacitação no uso de estratégias adaptadas do RECALL pela mãe. Duas categorias de estratégias foram avaliadas: as que elicitavam diretamente respostas da criança e as contingentes às suas respostas. No primeiro grupo, descritas no Quadro 1, estavam as incluídas no acrônimo CROWD, a pausa intencional e a atenção compartilhada. Vale destacar que, para esse estudo, duas modificações foram realizadas no protocolo original do RECALL. Primeiramente, a estratégia de completar foi dividida em duas (completar e completar fonológico ${ }^{5}$ ). Em segundo lugar, a estratégia de distanciamento não foi utilizada por ser considerada, pelas pesquisadoras, de difícil compreensão da criança. Ressalta-se que modificações no protocolo da Leitura Dialógica é uma prática comum, conforme evidenciado na literatura (TOWSON, FETTIG, FLEURY, ABARCA, 2017)

5 Completar fonológico, mesmo não sendo parte do programa original, foi acrescentado devido ao uso frequente que a mãe fazia dessa estratégia.

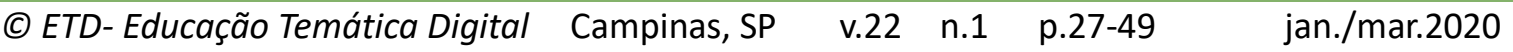


QUADRO 1 - Estratégias empregadas pela mãe para eliciar (diretamente) respostas da criança

\begin{tabular}{|c|c|c|}
\hline Estratégia & Definição & Exemplo \\
\hline $\begin{array}{l}\text { Atenção } \\
\text { compartilhada }\end{array}$ & $\begin{array}{l}\text { Estabelecer foco de atenção comum com a } \\
\text { criança por meio de três ações: apontar para } \\
\text { ilustrações do livro, verbalizar interjeições/tecer } \\
\text { comentários sobre a imagem e voltar a dirigir o } \\
\text { olhar para a criança }\end{array}$ & $\begin{array}{l}\text { Mãe: Olha! (aponta para a } \\
\text { imagem do leão na página } \\
\text { do livro e, em seguida, dirige } \\
\text { o olhar para a criança). }\end{array}$ \\
\hline Completar & $\begin{array}{l}\text { Verbalizar uma frase afirmativa do livro de forma } \\
\text { incompleta, fazendo uma pausa (silêncio) de três } \\
\text { segundos ao final da frase. }\end{array}$ & $\begin{array}{l}\text { Mãe: A vaca foi para a festa, } \\
\text { o leão foi para a festa, a rã foi } \\
\text { para a... (pausa de } 3 \text { seg.) }\end{array}$ \\
\hline $\begin{array}{l}\text { Completar } \\
\text { fonológico }^{6}\end{array}$ & $\begin{array}{l}\text { Verbalizar uma palavra do livro de forma } \\
\text { incompleta, fazendo uma pausa (silêncio) de três } \\
\text { segundos ao final da sentença. }\end{array}$ & $\begin{array}{l}\text { Mãe: A barata cantou "quem } \\
\text { quer casar com a senhora } \\
\text { bara.... (tinha)" }\end{array}$ \\
\hline Evocar & $\begin{array}{l}\text { Elaborar uma pergunta sobre eventos específicos } \\
\text { da história, que exijam rememorar a sequência } \\
\text { de fatos ocorridos. }\end{array}$ & $\begin{array}{l}\text { Mãe: O que Dona Baratinha } \\
\text { ia fazer todas as manhãs em } \\
\text { sua janela? }\end{array}$ \\
\hline $\begin{array}{l}\text { Pergunta com } \\
\text { final aberto }\end{array}$ & $\begin{array}{l}\text { Elaborar uma pergunta com múltiplas } \\
\text { possibilidades de respostas. }\end{array}$ & $\begin{array}{l}\text { Mãe: O que está } \\
\text { acontecendo nesta página? }\end{array}$ \\
\hline Perguntas Qu & $\begin{array}{l}\text { Elaborar uma pergunta cuja resposta seja a } \\
\text { nomeação de um substantivo ou verbo. Apontar } \\
\text { para a figura ao verbalizar a pergunta. }\end{array}$ & $\begin{array}{l}\text { Mãe: O que é isso?; O que } \\
\text { ela está fazendo?; Onde ela } \\
\text { mora?;Quem é esse? }\end{array}$ \\
\hline Inferências & $\begin{array}{l}\text { Elaborar uma pergunta cuja resposta não se } \\
\text { encontre no texto, mas precise de relacionar o } \\
\text { ouvido na história com conhecimento prévio. }\end{array}$ & $\begin{array}{l}\text { Mãe: Por que você acha que } \\
\text { o menino está feliz? }\end{array}$ \\
\hline $\begin{array}{l}\text { Identificação } \\
\text { emocional }\end{array}$ & $\begin{array}{l}\text { Elaborar perguntas sobre como o personagem } \\
\text { está se sentindo ou como a criança se sentiria se } \\
\text { estivesse no lugar do personagem. }\end{array}$ & $\begin{array}{l}\text { Mãe: Como você se sentiria } \\
\text { se caísse dentro de uma } \\
\text { panela de feijão? }\end{array}$ \\
\hline $\begin{array}{l}\text { Pausa } \\
\text { intencional }\end{array}$ & $\begin{array}{l}\text { Permanecer em silêncio por } 3 \text { seg. olhando para } \\
\text { a criança: (a) antes ou depois de virar a página } \\
\text { do livro ou (b) quando se aponta para alguma } \\
\text { imagem no livro e se olha para a criança com ar } \\
\text { interrogativo. }\end{array}$ & $\begin{array}{l}\text { Mãe: (ao virar a página do } \\
\text { livro) E daí, a Dona Baratinha } \\
\text { foi ... (faz silêncio e segura a } \\
\text { página do livro sem virar) }\end{array}$ \\
\hline
\end{tabular}

Fonte: Adaptado de Whalon et al., 2015.

O segundo conjunto de estratégias era empregado em decorrência do tipo de resposta dada pela criança. Elas incluíam a expansão do vocabulário, o elogio e a hierarquia de dicas visuais, conforme descrito no Quadro 2:

QUADRO 2 - Estratégias empregadas pela mãe em decorrência de resposta da criança

\begin{tabular}{l|l|l}
\hline Estratégia & Definição & Exemplo
\end{tabular}

6 Também chamado de Closura ou Fechamento Auditivo, é um dos vários mecanismos que o sistema auditivo usa para processar informação acústica. Essa capacidade permite entender e completar as partes faltantes de uma frase ou de uma palavra percebida através da audição (LAMÔNICA et. al., 2012; BELLIS, 2003).

(c) ETD-Educação Temática Digital $\quad$ Campinas, SP $\quad$ v.22 n.1 $\quad$ p.27-49 jan./mar.2020 


\begin{tabular}{l|l|l}
\hline $\begin{array}{l}\text { Expandir o } \\
\text { vocabulário }\end{array}$ & $\begin{array}{l}\text { Tecer comentários sobre a resposta correta } \\
\text { dada pela criança. }\end{array}$ & $\begin{array}{l}\text { Mãe: quem é essa? } \\
\text { Criança: barata. } \\
\text { Mãe: A barata simpática }\end{array}$ \\
\hline Elogiar & $\begin{array}{l}\text { Tecer comentários positivos sobre resposta da } \\
\text { criança a respeito do livro. Não considerar } \\
\text { comentários sobre comportamento }\end{array}$ & $\begin{array}{l}\text { Mãe: quem é essa? } \\
\text { Criança: barata. } \\
\text { Mãe: Isso! É a barata! }\end{array}$ \\
\hline $\begin{array}{l}\text { Hierarquia de } \\
\text { dicas visuais - } \\
\text { nível 1 }\end{array}$ & $\begin{array}{l}\text { Utilizar livreto de dicas visuais em caso de não } \\
\text { resposta /resposta incorreta. Apresentar 3 } \\
\text { opções de respostas no livreto. Leitor rotula } \\
\text { cada opção. }\end{array}$ & $\begin{array}{l}\text { Mãe: Essa é a barata, o grilo } \\
\text { ou o rato? (aponta para } \\
\text { cada figura ao verbalizar os } \\
\text { nomes) }\end{array}$ \\
\hline $\begin{array}{l}\text { Hierarquia de } \\
\text { dicas visuais - } \\
\text { nível 2 }\end{array}$ & $\begin{array}{l}\text { Após uso de hierarquia 1, se a criança apontar } \\
\text { para a opção incorreta, a pergunta deverá ser } \\
\text { formulada, sendo coberta a opção errada } \\
\text { (aquela apontada pela criança) e apresentadas } \\
\text { as outras duas opções. }\end{array}$ & $\begin{array}{l}\text { Criança: Aponta para o grilo } \\
\text { (resposta incorreta) } \\
\text { Mãe: Essa é a barata ou } \\
\text { rato? (tampa a imagem do } \\
\text { grilo e verbaliza os nomes } \\
\text { dos outros) }\end{array}$ \\
\hline $\begin{array}{l}\text { Hierarquia de } \\
\text { dicas visuais - } \\
\text { nível } 3 \text { (modelo } \\
\text { de resposta) }\end{array}$ & $\begin{array}{l}\text { Após o uso da hierarquia 2, se a criança apontar } \\
\text { para a segunda opção incorreta, o leitor deverá } \\
\text { cobrir as duas alternativas incorretas, verbalizar } \\
\text { e apontar para o item correto e pedir para a } \\
\text { criança repetir verbalmente a resposta. }\end{array}$ & $\begin{array}{l}\text { Criança: (aponta para o rato } \\
\text { resposta incorreta) } \\
\text { Mãe: Essa é barata (aponta } \\
\text { para a barata e cobre as } \\
\text { outras 2 opções). Diga, } \\
\text { barata (leva o dedo } \\
\text { indicador da criança até a } \\
\text { imagem) }\end{array}$ \\
\hline
\end{tabular}

Fonte: Adaptado de Whalon et al., 2015

O segundo objetivo do estudo foi avaliar os efeitos das estratégias empregadas pela mãe, descritas nos quadros 1 e 2, nas respostas da criança. Essas respostas, que poderiam ser emitidas de forma verbal, gestual ou pictográfica (utilizando imagens disponibilizadas no livreto), foram classificadas como corretas ou incorretas.

\subsection{Procedimentos}

Após a aprovação do projeto pelo Comitê de Ética em Pesquisa (Parecer 1.662.461), o estudo foi desenvolvido em nove etapas, tendo a duração de 20 semanas: (1) Avaliação; (2) Treinamento da assistente de pesquisa, (3) Seleção dos livros; (4) Linha de base, (5) Capacitação, (6) Elaboração do material para a intervenção (7) Intervenção, (8) Follow up; (9) avaliação do programa.

1. Avaliação - O objetivo dessa fase foi avaliar as demandas e potencialidades sociocomunicativas e comportamentais da criança, o seu grau de autismo, assim como a suas habilidades de letramento. A avaliação ocorreu por meio da aplicação dos quatro instrumentos de avaliação previamente citados.

2. Treinamento dos assistentes de pesquisa - 0 treinamento foi finalizado quando as assistentes e a agente de intervenção alcançaram um índice de concordância de $75 \%$ em três sessões para cada uma das variáveis analisadas.

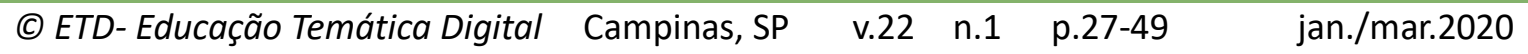


3. Seleção dos livros de linha de base - A agente de intervenção e a mãe elegeram, inicialmente, seis livros para serem utilizados durante o programa. Para ser selecionado, o livro deveria conter narrativas simples, de interesse da criança, assim como incluir ilustrações claras, que oportunizavam a identificação do estado emocional dos personagens. Ademais, a criança não poderia ter tido contato prévio com a obra.

4. Linha de base - A mãe foi instruída a contar histórias, de maneira espontânea (sem receber instrução alguma por parte da agente de intervenção), a seu filho. Nessa prática foi solicitada a ler um mesmo livro, duas vezes por semana. As sessões foram conduzidas na residência da díade e videografadas pelo pai da criança. A estratégia de hierarquia de dicas, com o uso dos livretos, não foi utilizada. Nas análises foram calculadas as frequências de uso de cada uma das estratégias do programa de leitura (quadros 1 e 2) que foram aplicadas, espontaneamente, pela mãe, assim como os tipos de respostas da criança (quadro 3). A fase de linha de base foi finalizada quando foi observada uma estabilidade na resposta da mãe no uso espontâneo de, pelo menos, três estratégias identificadas nos quadros 1 e 2 . No total foram lidos seis livros, em um período de seis semanas.

5. Capacitação - A mãe foi capacitada pela agente de intervenção a utilizar as estratégias que não estavam presentes em seu repertório, durante a linha de base. O programa teve duração de um mês, com dois encontros presenciais e três encontros virtuais. No treinamento foram utilizadas dramatizações, explicações teóricas sobre as estratégias, assim como a autoscopia (SADALLA, LAROCCA, 2004), que consistiu da visualização das sessões videografadas na linha de base. Ao término das duas primeiras capacitações, a agente de intervenção e a mãe escolheram seis livros contemplando as mesmas características das obras selecionadas na fase linha de base.

6. Elaboração do material para a intervenção - Nesta etapa foram criados dois roteiros de perguntas para cada um dos seis livros utilizados na intervenção e dois livretos diferentes, por livro, contendo as dicas visuais. 
7. Intervenção - Após cada sessão de capacitação, a mãe era orientada a utilizar, com o filho, as estratégias aprendidas. Assim como na linha de base, foi instruída a ler o mesmo livro duas vezes por semana, em dois dias distintos. Cada livro continha dois roteiros de perguntas elaborados pelas pesquisadoras. O primeiro, que deveria ser lido no primeiro dia da intervenção, incorporava perguntas qu, e o roteiro 2 acrescentava as perguntas de completar, final aberto, identificação emocional, inferência e evocar, descritos no quadro 1. Ademais, caberia a ela incorporar as estratégias descritas no quadro 2 , considerando a responsividade da criança durante a leitura. Não foram incluídas, no roteiro, perguntas de completar fonológico, visto ter sido uma estratégia apresentada por ela durante a linha de base. Assim como na linha de base, as sessões de intervenção foram videografadas pelo pai e posteriormente analisadas. Nessa fase da pesquisa foram lidos seis livros em um período de seis semanas.

8. Follow-up - A mãe foi instruída a ler três livros para a criança, com intervalos de quinze dias para cada obra. Assim como nas fases anteriores, foi solicitado que lesse o mesmo livro duas vezes, em dias distintos. As sessões deveriam ser videografadas e a agente de intervenção não forneceria qualquer feedback nessa etapa, tampouco produziria os livretos com as perguntas.

9. Avaliação do programa - Os efeitos do programa no repertório da díade foram avaliados por meio de gráficos com registros das frequências de ocorrência de cada comportamento. Diários de campo foram considerados para a análise qualitativa dos dados. Por fim, uma entrevista semiestruturada foi utilizada para avaliar a validade social da pesquisa.

\section{RESULTADOS E DISCUSSÃO}

Os resultados desse estudo serão apresentados considerando três eixos de análise: (a) Avaliação da Criança; (b) Efeito da capacitação no comportamento da mãe; (c) Efeitos da capacitação no comportamento da criança.

\subsection{Avaliação da Criança}

Diego apresentava autismo leve/moderado (CARS $=32$ pontos), alterações sociocomunicativas, caracterizada por dificuldades de manter contato visual, prejuízos na compreensão de comandos verbais complexos, ecolalia e vocabulário expressivo limitado. 0 menino evidenciava hipersensibilidade tátil e dificuldades de autorregulação.

A escala HELPA revelou que o uso de materiais impressos era constante no ambiente familiar e que o menino apresentava interesse em livros. Além de saber manuseá-los, tinha conhecimento da escrita compatível com sua idade. A despeito desses resultados, obteve 18 pontos de escore total (27,69\%) na Escala de Letramento Emergente, demonstrando

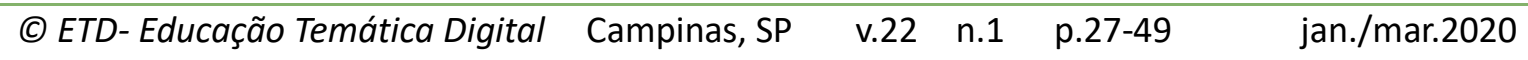


limitadas habilidades de letramento. Tinha pouca consciência fonológica e desconhecimento da função das palavras impressas.

\subsection{Efeitos da capacitação no comportamento da mãe}

Dois prismas serão considerados na análise do comportamento materno. O primeiro consiste na avaliação das seis (6) estratégias incluídas no script (elaborado pelas pesquisadoras) na fase de intervenção. Ou seja, as perguntas de: completar, qu, final aberto, inferência, evocar e identificação emocional. Para esse grupo, as mudanças observadas entre as fases de linha de base e follow-up serão o foco de análise. Não serão avaliadas, portanto, as frequências na fase de intervenção, onde as perguntas foram elaboradas pelas pesquisadoras.

O segundo engloba as cinco (5) estratégias não incluídas no script fornecido na fase de intervenção. Em outras palavras, as estratégias de completar fonológico, a atenção compartilhada, a pausa intencional, o elogio e a expansão. Nesse grupo, as três fases do estudo serão consideradas na análise.

A Tabela 1 apresenta a porcentagem de uso das 11 estratégias nas três fases do estudo. Esse valor foi calculado dividindo a frequência computada de cada estratégia pela soma total das 11 estratégias, multiplicado por 100.

Tabela 1 - Porcentagem de uso das estratégias por parte da mãe nas três fases do estudo

\begin{tabular}{c|c|c|c}
\hline \multirow{2}{*}{ Estratégia } & \multicolumn{3}{|c}{ Fases } \\
\cline { 2 - 4 } & Linha de base & Intervenção & Follow-up \\
\hline Perguntas-Qu & $42.8 \%$ & $36.5 \%$ & $35.76 \%$ \\
Completar & $30.1 \%$ & $7.1 \%$ & $19.39 \%$ \\
Atenção compartilhada & $6 \%$ & $5.4 \%$ & $6.67 \%$ \\
Completar fonológico & $12 \%$ & $2.5 \%$ & $13.94 \%$ \\
Final aberto & $6 \%$ & $4.6 \%$ & $1.21 \%$ \\
Evocar & $1.2 \%$ & $3.3 \%$ & $0.0 \%$ \\
Inferências & $1.2 \%$ & $8.3 \%$ & $0.0 \%$ \\
Identificação emocional & $0.6 \%$ & $2.9 \%$ & $3.03 \%$ \\
Pausa intencional & $0 \%$ & $0.4 \%$ & $0.0 \%$ \\
Elogio & $0 \%$ & $2.5 \%$ & $8.48 \%$ \\
Expansão & $0 \%$ & $26.6 \%$ & $11.52 \%$ \\
\hline
\end{tabular}

Fonte: As autoras

De uma forma geral, os dados sugerem que o programa de capacitação teve pouco impacto na frequência de uso de perguntas-qu, tanto na pausa intencional quanto na atenção compartilhada. No primeiro caso, as perguntas "de fato" apresentam alta frequência e relativa estabilidade comparando linha de base e follow-up. Conforme mencionado em nossa literatura, esse tipo de pergunta é de mais fácil compreensão pela criança com autismo (VAN KLEECK; VANDER WOUDE; HAMMETT, 2006). Isso é corroborado

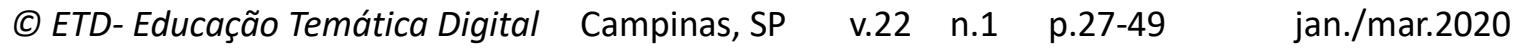


pelos dados da Tabela 2, apresentados na sequência, que revelam o bom desempenho de Diego em responder questões dessa modalidade.

O limitado uso da pausa intencional e da atenção compartilhada pode ser justificado pelo próprio repertório de Diego, que não demandava o uso das estratégias. No primeiro caso, o objetivo de permanecer em silêncio em determinados momentos da leitura é estimular as iniciativas de interação da criança (WHALON et al., 2015). Conforme sugerido na Tabela 3, a frequência de iniciativas de interação do menino era alta, tornando, assim, desnecessário o uso da pausa. No segundo caso, a estratégia de atenção compartilhada visa estabelecer um foco de atenção comum por meio do direcionamento do olhar da criança para o livro. Trata-se de comportamento mediador empregado quando a criança se mostra pouco engajada na tarefa de leitura, falhando em manter o foco de atenção na narrativa. Considerando o bom nível de engajamento do menino, pouco foi necessário o uso do referido método.

A estratégia de completar era, primordialmente, empregada como frase concludente dos relatos. Assim, ao final da história, a mãe dizia: e viveram felizes para..., fazendo uma pausa para que a criança respondesse com a palavra sempre. Dessa forma, utilizava o texto previsivel ou texto repetitivo, presentes em narrativas que contêm frases ou sequências de palavras idênticas, que se repetem ao longo da história. Devido ao padrão recorrente e a familiaridade do contexto narrativo, os livros com texto previsível são indicados para crianças que estão aprendendo a ler e a escrever (SOURESHJANI; SAFIKHANI, 2013).

Os dados da Tabela 1 sugerem a diminuição na frequência de uso do completar e completar fonológico durante a intervenção e uso crescente na fase do follow-up. Essa tendência pode ser atribuída à introdução das novas estratégias na fase da intervenção, que delimitou, por meio do script, o repertório da mãe. Observa-se, no entanto, que a mãe voltou a empregar essas mesmas estratégias com frequência compatível à linha de base, na fase de follow-up. Esse padrão pode ser atribuído ao seu nível de conforto, como também, conforme observado na Tabela 2, à boa responsividade de Diego a esses tipos de perguntas. Essas hipóteses são corroboradas pela seguinte afirmativa:

Uma coisa puxa a outra, fico mais confortável (em usar as que ele tem que completar e as de qu-) porque ele dá as respostas. Fico mais desconfortável nas que ele não consegue entender. (ENTREVISTA DE VALIDAÇÃO SOCIAL, 2 de junho,2017).

Da mesma forma que a mãe fala de sua receptividade ao uso das questões de completar, revela o desconforto em empregar perguntas de difícil compreensão para o filho. Esse era o caso, particularmente, das interrogações de final aberto, em que Diego apresentou fraco desempenho, conforme observado na Tabela 2. Assim, o limitado uso dessa estratégia ao longo do estudo pode ser devido ao incômodo da mãe em elaborar perguntas dessa natureza. De fato, a dificuldade de pessoas com autismo em responder adequadamente questões não estruturadas está documentada na literatura. (JAHR, 2001).

(C) ETD-Educação Temática Digital Campinas, SP $\quad$ v.22 n.1 $\quad$ p.27-49 jan./mar.2020 
As perguntas de evocar e as de inferência foram identificadas na linha de base, aumentaram durante a intervenção, mas foram extintas no follow-up. A despeito do reconhecimento de sua importância, a mãe julgava que o filho teria dificuldades em compreender essas perguntas, como sugere o seguinte fragmento:

[...] essas de (estratégia) evocar achei as mais difíceis... essa aí também, (inferência) era muito difícil. $O$ que que já passou... (evocar) ... porque eu acho que assim, $o$ "achar" você pensa... ele não tem ainda a compreensão, por isso que as dicas visuais eram tão importantes... (ENTREVISTA DE VALIDAÇÃO SOCIAL, 2 de junho,2017).

Conforme foi observado, a mãe compreendia que o menino não seria capaz de responder a uma questão que aludisse ao passado, tampouco compreender aspectos mais subjetivos de uma narrativa (o "achar"). Esse fenômeno é compatível com os achados de van Kleeck, Vander Woude e Hammett (2006), que observaram baixa frequência no uso da linguagem inferencial de pais de crianças com déficits de linguagem, durante a interação com os filhos, em comparação com pais de crianças com desenvolvimento típico.

Outro fator que justifica a não incorporação dessas estratégias, pela mãe, é o reduzido tempo fornecido para a sua assimilação, assim como a falta de ajuste ao seu estilo de interação. Nesse cenário, dados de outros pesquisadores salientam a necessidade de fornecer mais tempo para que os cuidadores assimilem novas formas de interação (AUTOR et al., 2016; RICCO LUCATO SIGOLO, 2000). Ademais, é importante destacar que um mesmo costume compartilhado por diferentes culturas, como por exemplo, a leitura de histórias para crianças, também possui especificidades exclusivas para cada grupo, sendo essencial considerá-las (RICCO LUCATO SIGILO, 2000). Nesse sentido, a mãe fala do desafio em incorporar um novo estilo de interação com o filho, como revela no seguinte fragmento:

[...] não era só aquela leitura que eu fazia antes, aquela leitura que eu lia por ler, e eu ia deixando, se ele prestasse atenção tudo bem e senão tudo bem também, $e$ tinha perguntas que iam ser feitas e que se esperava alguma coisa dele... (ENTREVISTA DE VALIDAÇÃO SOCIAL, 2 de junho,2017).

Embora não tenha adotado, em seu repertório, algumas das estratégias propostas, outras pareceram se adequar às rotinas de leitura com o filho. Foi o que ocorreu, particularmente, com as dicas visuais, conforme revela a Figura 2. Nesse gráfico, é apresentada a frequência com que o menino respondeu perguntas espontaneamente e com o apoio das imagens do livreto, fornecidas pela mãe, ao longo da fase de intervenção. 
Figura 2 - Modalidade de respostas da criança na fase de intervenção

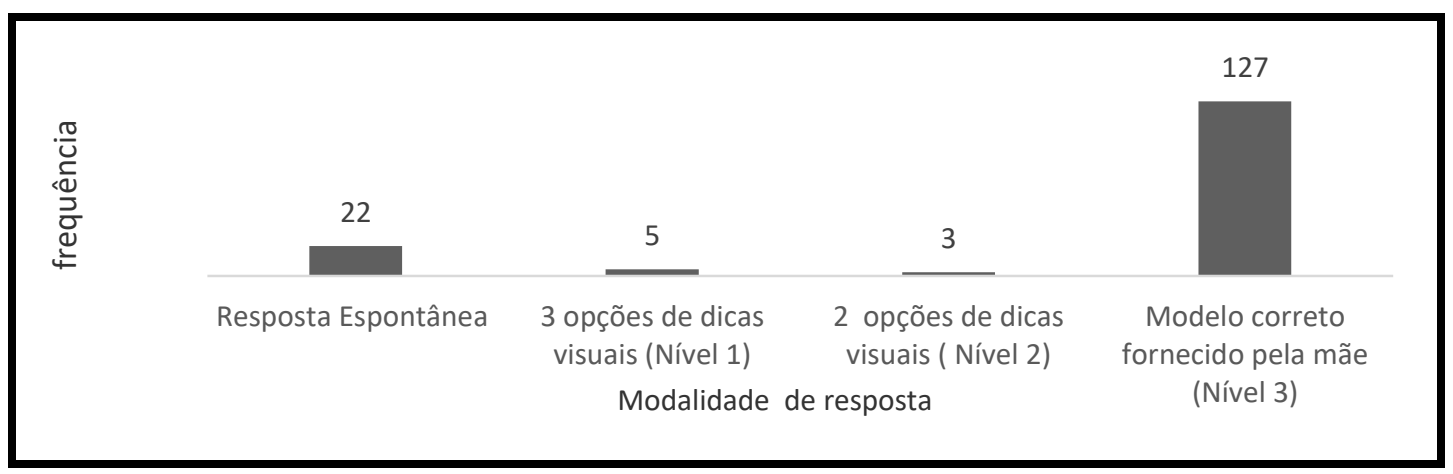

Fonte: As autoras

Observa-se que das 157 respostas de Diego na fase de intervenção, 22 (14\%) foram espontâneas, sem o uso dos pictogramas. No restante (86\%), ele contou com o apoio dos pictogramas. Ademais, em entrevista de validade social, a mãe declarou:

Eu acho que as dicas visuais foram importantíssimas, eu acho até para ele entender o que é que a gente estava buscando, agora tinha perguntas, ele tinha que responder, não era como antes, ler por ler. (ENTREVISTA DE VALIDADE SOCIAL, 2 de junho,2017).

A fala da mãe tem respaldo em resultados de pesquisas que indicam que os recursos visuais auxiliam a desenvolver a linguagem expressiva, receptiva, além de favorecerem o estabelecimento da atenção compartilhada para crianças com TEA (PATTEN; WATSON, 2011; WHALON et al., 2015). Conforme observado no relato da mãe, o uso de dicas visuais era essencial para que o menino respondesse corretamente às perguntas. Sem embargo, ela não as usou durante o follow-up por julgar que o filho havia apresentado melhoras nas respostas. O segmento, em seguida, no qual a mãe narra a sua experiência na fase de follow-up, sustenta essa hipótese:

(...) eu sei que ele melhorou demais, na forma dele de escutar as histórias. Fiquei na maior dúvida se usar ou não (as ajudas visuais), pensei, sentei, peguei, assim do jeito que você, aí pensei, não, vou tentar seguir as mesmas estruturas de perguntas, mas, mais livre sem anotação, sem as dicas, vamos ver como ele responde, então pensei, vamos assim (sem ajudas visuais) porque ele estava respondendo, aí eu gostei de fazer dessa forma, (ENTREVISTA DE VALIDADE SOCIAL, 2 de junho,2017).

Quando questionada sobre a continuidade ou não das ajudas visuais nas rotinas de leitura, a mãe respondeu negativamente: "Agora, neste momento, eu acho que não porque ele está dando, você viu que ele está dando as respostas bem assim" (ENTREVISTA DE VALIDADE SOCIAL, 2 de junho, 2017). 
A adaptação de estratégias interventivas às especificidades de um contexto, considerando as variáveis situacionais é amplamente discutida na literatura educacional (LUBAS; MITECHEL; DE LEO, 2016). Sendo assim, foi observado que a mãe adaptou a hierarquia de dicas, substituindo os recursos visuais por perguntas estruturadas. Esse fenômeno foi observado durante o follow-up, em que ela não construiu os livretos (com dicas visuais), mas forneceu, verbalmente, opções de resposta, conforme observado no seguinte segmento:

\author{
Mãe: "Como é o nome do irmãozinho da Luna?" (Pergunta-Qu) \\ Criança: "Da Luna" (ecolalia) \\ Mãe: "O irmão da Luna?" (Pergunta-Qu) \\ Criança: "Irmão da Luna" (ecolalia) \\ Mãe:" Como é o nome?" (Pergunta-Qu) \\ Criança: "Luna, aí, é Luna" \\ Mãe: "A Luna, e o nome do irmão dela é...?" (Completar) \\ Criança: "Cláudio..." (resposta incorreta) \\ Mãe: "Cláudio é o nome do bichinho" (expansão) \\ Criança: "Do bichinho" (ecolalia) \\ Mãe: "Bichinho da Luna é Cláudio, o irmão é...?" (Completar) \\ Criança: "É Júpiter" (resposta correta) \\ Mãe: "É o Júpiter, muito bem!" ('Elogio') (REGISTRO DE CAMPO, NATAL-RN, 3 DE \\ MAIO, 2017)
}

Conforme observado no fragmento acima, no momento em que Diego respondeu incorretamente a pergunta, a mãe simplificou a questão. Em seguida, ela forneceu feedback, corrigindo a sua resposta. Por fim, empregou perguntas mais simples, envolvendo o completar.

É necessário observar que essa estratégia auxiliou a cessar as respostas ecolálicas da criança. Considerando que a ecolalia decorre, dentre outros motivos, da falta de compreensão verbal (HEZTRONI, TAUNNUS, 2004), simplificar a pergunta pode ter sido uma estratégia efetiva para diminuí-la. Vale destacar que, a despeito da função comunicativa da ecolalia, essa alteração pode conduzir a falhas na comunicação, provocar dificuldades na socialização e/ou alterações no aspecto pragmático da linguagem (HEZTRONI; TAUNNUS, 2004; NEELY, et al., 2015).

Os efeitos do programa de capacitação foram mais notórios na incorporação das estratégias de expansão e elogio, que apresentaram crescimento nas fases de intervenção e foram mantidas no follow-up. Assim, além de ampliar as respostas do filho, tecendo comentários referentes às respostas corretas - como previsto na expansão - a mãe passou a fornecer, também, expansões frente às respostas incorretas. Os trechos a seguir exemplificam esses comportamentos: 
Mãe: “Eles estão conversando com quem?” (pergunta qu)

Criança: "Com a lua..."

Mãe: "Com a lua, isso mesmo!" (elogio) "A Luna, o L. o júpiter e o Claudio estão conversando com a lua". (expansão)

(REGISTRO DE CAMPO, NATAL-RN, 3 DE MAIO, 2017).

Mãe: “E como é o nome desse jogo que tem esses números sabe?"... (aponta para a ilustração) (pergunta Qu)

Criança: vocalização ininteligível

Mãe:" É o jogo de a..". (completar fonológico)

Criança: "De a $\mathrm{mm}$. ...

Mãe: "Ama..". (completar fonológico)

Criança: "amarelo" (resposta incorreta)

Mãe: "Amarelinha". "O nome do jogo é amarelinha". (expansão do modelo correto) (REGISTRO DE CAMPO, NATAL-RN, 3 DE MAIO, 2017)

O protocolo utilizado nesse estudo preconiza que, frente a uma resposta correta, o leitor deva expandir a linguagem e elogiar a criança. Os dados da Tabela 1 sugerem que, após o programa de capacitação, o elogio foi incorporado ao repertório de respostas da mãe. Isso é confirmado pelo aumento de sua frequência nas fases de intervenção e follow-up. Vale destacar, também, que o aumento no número de respostas corretas emitidas pela criança explica, em parte, o aumento na frequência de elogios por parte da mãe.

Embora o foco da capacitação fosse a mãe, o pai era partícipe do programa, uma vez que era o responsável pelas filmagens das rotinas de leitura. Nesse cenário, a intervenção impactou não apenas o comportamento da díade mãe-criança, mas também o repertório de respostas paternas, conforme assinalado no relato da mãe:

E ele (o pai) pegava algumas coisas também, tinha dias que ficava com Diego e ficava perguntando. Algumas coisas eu o vi perguntando parecido com que a gente tinha perguntado na estória, sabe? Até se tivesse com qualquer coisa, às vezes estava com uma revista, com Diego, ele ficava perguntando, que ela está fazendo aqui, Diego. Isso que a gente virou meio que um habito. (ENTREVISTA DE VALIDAÇÃO SOCIAL, 2 de junho,2017).

\subsection{Efeitos da capacitação no comportamento da criança}

A Tabela 2 apresenta a porcentagem de respostas corretas da criança às perguntas elaboradas pela mãe nas três fases do estudo. 
Tabela 2 - Porcentagem de respostas corretas da criança

\begin{tabular}{l|c|c|c}
\hline \multirow{2}{*}{ Tipo de pergunta } & Linha de base & Intervenção & Follow-up \\
\cline { 2 - 4 } & $14,9 \%$ & $33,3 \%$ & $42,9 \%$ \\
Perguntas-Qu & $59,6 \%$ & $40,0 \%$ & $27,3 \%$ \\
Completar & $25,5 \%$ & $20,0 \%$ & $24,7 \%$ \\
Final aberto & $0 \%$ & $3,3 \%$ & $1,3 \%$ \\
Evocar & $0 \%$ & $3,3 \%$ & $*$ \\
Inferências & $0 \%$ & $0 \%$ & $*$ \\
Identificação & $0 \%$ & $0 \%$ & $3,9 \%$ \\
emocional & & & \\
\hline
\end{tabular}

* não resposta da criança devido ao não uso da estratégia por parte da mãe

Fonte: As autoras

Conforme salientado na Tabela 2, a frequência de respostas corretas às perguntas qu, pela criança aumentou expressivamente ao longo do estudo. Essa melhoria pode ser atribuída a dois fatores. Primeiramente, ao uso constante dessa modalidade de pergunta por parte da mãe, permitindo à criança ter mais prática com as respostas esperadas. Adicionalmente, como sinalizado por van Kleeck e colaboradores (2006), as crianças desenvolvem, primeiramente, habilidades para compreender perguntas e sentenças de fato ou concretas, para depois interpretar perguntas que empregam a linguagem inferencial.

O desempenho de Diego nas perguntas de completar, ao longo das três etapas do estudo, evidenciou uma relativa queda. Esse padrão pode ser justificado considerando a frequência absoluta das respostas ao invés de porcentagens. No follow-up, por exemplo, Diego respondeu corretamente sete vezes menos que na linha de base. Ademais, em termos qualitativos, o nível de complexidade das perguntas de completar foi maior no follow-up. Em algumas ocasiões as questões demandavam respostas mais subjetivas. Por exemplo, no momento em que o personagem do livro Minha primeira experiência: no dentista, parece amedrontado, a mãe diz: ele está sentindo.... Em seguida faz uma pausa, demandando que a criança respondesse com a palavra medo. Essa resposta requer a capacidade de fazer inferências para compreender o sentimento. Como documentado na literatura, essa habilidade é tipicamente deficitária em populações com TEA (CARNAHAN; WILLIAMSON; CHRISTMAN, 2011; LUCAS; NORBURY, 2015; FLORES; GANZ, 2009).

A porcentagem de acertos às perguntas de completar fonológico se manteve relativamente estável. Em comparação com as demais estratégias, o desempenho de Diego foi bom. Assim como nas perguntas qu, a familiaridade do menino com esse repertório da mãe justifica esse resultado. Em contrapartida, nas de final aberto, a porcentagem de acertos foi expressivamente menor, embora com tímida melhoria na intervenção e follow-up.

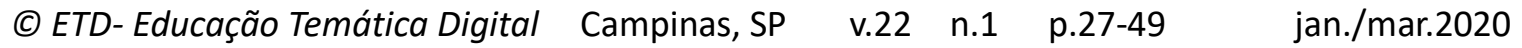


Além de ter elaborado poucas perguntas dessa natureza, a mãe tipicamente direcionava a réplica, impedindo que a criança elaborasse uma resposta às perguntas abertas, como exemplificado no trecho, a seguir:

A mãe pergunta: "O que que está acontecendo aqui?" "O pai da menininha está mexendo em que?" "Olha aqui, que que ele está pegando, o pai da menininha?" (REGISTRO DE CAMPO, NATAL-RN, 25 DE MARÇO, 2017).

No exemplo acima, embora a mãe tenha elaborado uma pergunta aberta, falhou em permitir que o filho a respondesse, direcionando a resposta por meio de uma questão mais simples, do tipo pergunta qu.

Os resultados apresentados na Tabela 2 sugerem que a compreensão da leitura oral de Diego assemelha-se ao padrão de desenvolvimento de uma criança neurotípica, onde o entendimento de perguntas factuais antecede ao de questões de cunho mais inferencial. De fato, o menino apresentou dificuldades em responder corretamente às perguntas mais subjetivas e abstratas, ou seja, as de identificação emocional, inferência e evocação. Dentre essas três modalidades, a primeira apresentou ligeira ascensão. Das cinco vezes em que a mãe a empregou, Diego respondeu corretamente a três.

Além de mudanças quantitativas, é interessante observar a melhora qualitativa nas respostas do menino ao longo das rotinas de leitura. Durante a apreciação do livro $A$ Caixa de Segredos, a mãe aponta para o rosto de uma personagem e diz $O$ que que a menininha está sentindo? olha para o rostinho dela. Em seguida o menino responde: Triste... está com raiva... está feliz, sugerindo compreender tratar-se de uma pergunta sobre sentimentos, mas evidenciando dificuldades em identificar a afeição do personagem. Em uma página adiante, a mãe aponta para o rosto da mesma personagem e pergunta o que que a menininha está sentindo, Diego? e a criança responde corretamente: não... tá... triste (pausa entre cada palavra), tá feliz.

Com o objetivo de mensurar se o programa afetou o comportamento sociocomunicativo de Diego, foram registradas as frequências de iniciativas de interação do menino, durante as rotinas de leitura. Assim, foram contabilizados as perguntas e os comentários, elaborados por Diego, nas modalidades verbal ou gestual, no decorrer das sessões. Vale destacar que não foram consideradas respostas às perguntas da mãe, tampouco expressões de protesto da criança, como: não e não quero. Ademais, apenas os turnos comunicativos relacionados à história foram incluídos. Para calcular a média de iniciativas de interação por livro foram divididas as frequências de iniciativas de interação, por fase, pela quantidade de livros lidos, conforme registrado na Tabela 3: 
Tabela 3 - Número de livros, frequência de iniciativas e média de iniciativas de interação, da criança, por livro.

\begin{tabular}{l|c|c|c}
\hline Fase & Número de livros lidos & Frequência de iniciativas & Média de iniciativas por livro \\
\hline Linha de base & 6 & 22 & 3,6 \\
\hline Intervenção & 6 & 32 & 5,4 \\
\hline Follow-up & 3 & 25 & 8,3 \\
\hline
\end{tabular}

Fonte: As autoras

Além do expressivo aumento na frequência de iniciativas após o programa de capacitação, dados qualitativos produzidos ao longo do estudo revelaram mudanças nas respostas do menino em termos de diversidade de vocabulário, incluindo uso de artigos, substantivos, adjetivos e verbos; número de palavras por frase e; nível de participação nos diálogos.

As nomeações produzidas na fase de linha de base eram, em sua maioria, de um só vocábulo, tipicamente, um substantivo (ex: tomate), substantivos com artigos (ex: a pipa) ou frases completas que funcionavam como uma só palavra, como era uma vez e viveram felizes para sempre. Durante a intervenção, as construções sintáticas tornaram-se mais complexas, com o emprego de verbos, substantivos e artigos. Isso foi, particularmente, observado no livro $E$ ainda o dente doía, quando o menino verbalizou quebrou o dente quando a mãe virou a página e o menino observou a imagem de um jacaré com o dente partido. Ou, ainda olha, estão "bincando", ao comentar, espontaneamente, sobre os personagens em uma piscina.

$\mathrm{Na}$ fase de follow-up foram observadas frases contendo de três a quatro palavras. Na leitura do livro Lucas brincando com o show da Luna!, por exemplo, foram registradas as expressões: É a lua, de comer, banana, agora é da banana e, por fim, Nossa! e este quem $f a z$ ?, solicitando `a mãe que verbalizasse o som emitido pelo animal retratado na história. Adicionalmente, o menino fez correções na produção, participando de pequenos diálogos com a mãe. Esse comportamento é evidenciado no seguinte fragmento, quando o menino observa a figura de um dinossauro no livro A Caixa de Segredos:

Criança: "guau-guau-guau"

Mãe: "Dinossauro faz guau-guau-guau]?"

Criança: "Dinossauro ahhhh" (menino abre a boca imitando o desenho e fazendo o barulho) (REGISTRO DE CAMPO, Natal, RN, 3 de MAIO, de 2016) 


\section{CONSIDERAÇÕES FINAIS}

Em consonância com a literatura, os resultados dessa pesquisa revelam os efeitos promissores da leitura dialógica adaptada para crianças com TEA. Considerando as variáveis situacionais discutidas nesse artigo, a adaptação do protocolo RECALL foi imperativa. Das onze estratégias apresentadas pela agente de intervenção, a mãe incorporou quatro ao seu repertório de leitura. A não adoção das demais estratégias foi atribuída a quatro fatores: (a) ao nível de responsividade do menino, que dispensava o uso de algumas práticas; (b) pela mãe julgar que o filho não compreenderia questões abstratas; (c) por essas práticas não se adequarem ao seu estilo de interação e; (d) pela brevidade do estudo que, possivelmente, não forneceu tempo suficiente para que a mãe incorporasse as novas práticas interventivas.

As mudanças de comportamento da mãe impactaram as respostas do filho, que ampliou: (a) o número de acertos tanto às perguntas factuais quanto às mais subjetivas; (b) a frequência de iniciativas de interação, (c) o número de palavras empregadas por frase e (d) a complexidade sintática das respostas verbais. Ademais, em alguns episódios foi observada diminuição de respostas ecolálicas da criança.

Por fim, vale mencionar que, em programas dessa natureza, é importante que o cuidador tenha a chance de selecionar as práticas interventivas que mais lhe adéquem. Nesse cenário, é recomendado que um conjunto de estratégias empiricamente validadas seja disponibilizado pelo agente de intervenção. No presente estudo a mãe salientou a importância de ter experimentado práticas inexistentes em seu repertório. Seus registros verbais, que justificaram a adoção ou o descarte das estratégias apresentadas, servirão de alicerce para o aperfeiçoamento do programa, que deverá ser replicado com outras díades.

\section{REFERÊNCIAS}

AMBRIDGE, Ben; BANNARD, Colin; JACKSON, Georgina. Is grammar spared in autism spectrum disorder? Data from judgments of verb argument structure overgeneralization errors. Journal of Autism and Developmental Disorders, v. 45, n.10, p. 3288-3296, 2015.

BELLIS, Teri. Assessment and management of central auditory processing disorders in the educational setting from science to practice. 2.ed. San Diego, Calif.; London: Singular Publishing, 2003.

CARNAHAN, Christina; WILLIAMSON, Pamela; CHRISTMAN, Jennifer. Linking cognition and literacy in students with autism spectrum disorder. Teaching Exceptional Children, v. 43, n. 6, p. 54-62, 2011. 
DAVIDSON, Meghan; KAUSHANSKAYA, Margarita; ELLIS WEISMER, Susan. Reading comprehension in children with and without ASD: the role of word reading, oral language, and working memory. Journal of Autism and Developmental Disorders, v.48, n.10, p.35243541, oct. 2018. doi: 10.1007/s10803-018-3617-7.

EIGSTI, Inge-Marie et al. Language and cognitive outcomes in internationally adopted children. Development and Psychopathology, v.23, n.02, p.629-646, 2011.

FLEURY, Verónica et al. Promoting active participation for preschoolers with autism spectrum disorder: a preliminary study. Child Language Teaching and Therapy, v.30, n. 3, p. 273-288, 2014.

FLEURY, Verónica; SCHWARTZ, Ilene. S. A modified dialogic reading intervention for preschool children with autism spectrum disorder. Topics in Early Childhood Special Education, v. 37, n. 1, p. 16-28, 2016.

GANZ, Jennifer; FLORES, Margaret. The effectiveness of direct instruction for teaching language to children with autism spectrum disorders: identifying materials. Journal of Autism and Developmental Disorders, v. 39, n.1, p. 75-83, 2009.

GUEVARA, Víctor; QUEIROZ, Lara; FLORES PFEIFFER, Eileen. Leitura dialógica adaptada para uma criança com transtorno do espectro autista: um estudo preliminar. Cadernos de PósGraduação em Distúrbios do Desenvolvimento, v.17, n.1, p.87-99, 2017.

GOUGH, Philip; TUNMER, William. Decoding, reading, and reading disability. Remedial and Special Education, v.7, n. 1, p. 6-10, 1986.

HETZRONI Orit; TANNOUS Juman. Effects of a computer-based intervention program on the communicative functions of children with autism. Journal of Autism and Developmental Disorders, v. 34, n. 2, 2004

JAHR, Erik. Teaching children with autism to answer novel wh-questions by utilizing a multiple exemplar strategy. Research in Developmental Disabilities, v.22, n.5, 407-423, 2001.

KADERAVEK, Joan; PENTIMONTI Jill; JUSTICE, Laura. Children with communication impairments: caregivers' and teachers' shared book-reading quality and children's level of engagement. Child Language Teaching and Therapy, v. 30, n. 3, p. 289-302, 2014.

LUCAS, Rebecca; NORBURY, Courtenay. Making inferences from text: it's vocabulary that matters. Journal of Speech, Language, and Hearing Research, v. 58, p. 1224-1232, 2015.

LUBAS, Margaret; MITCHEL, Jennifer; DE LEO, Gianluca. Evidence-based practice for teachers of children with autism: a dynamic approach. Intervention in School and Clinic, v. 51, n. 3, p. 188-193, 2016.

LAMÔNICA, Dionisia, et al. Desempenho psicolinguístico e escolar de irmãos com mielomeningocele. Rev. CEFAC, v.14 n.4, p.763-769, 2012.

(C) ETD- Educação Temática Digital $\quad$ Campinas, SP $\quad$ v.22 n.1 $\quad$ p.27-49 jan./mar.2020 
LANTER, Elizabeth; WATSON, Linda. Promoting literacy in students with ASD: the basics for the SLP. Language, Speech, and Hearing Services in Schools, v. 39, p. 33-43, 2008.

LUCAS, Rebecca; NORBURY, Courtenay. Making inferences from text: it's vocabulary that matters. Journal of Speech, Language, and Hearing Research, v. 58, p.1224-1232, 2015.

MCKENZIE, Ward. Parent implemented adapted dialogic reading with preschoolers with autism 2018. Masters Theses \& Specialist, Western Kentucky University Projects. Disponível em: https://digitalcommons.wku.edu/theses/2450. Acesso em: 4 de março

NATION, Kate. et al. Patterns of reading ability in children with autism spectrum disorder. Journal of Autism and Developmental Disorders, v. 36, p. 911-919, 2006.

NATIONAL EARLY LITERACY PANEL [NELP]. Developing early literacy: report of the National Early Literacy Panel: a scientific synthesis of early literacy development and implications for intervention. [Jessup, Md.]: [National Institute for Literacy], [2008].

NEELY, Leslie, et al. Treatment of echolalia in individuals with autism spectrum disorder: a systematic review. Review Journal of Autism and Developmental Disorders, v.3, issue 1, p. 82-91, march 2016.

PATTEN Elena, WATSON Linda. Interventions targeting attention in young children with autism. The American Journal of Speech-Language Pathology. v. 20, n. 1, p. 60-9. Epub 2010 Aug 25. 2011.

PEREIRA Alessandra; RIESGO Rudimar; WAGNER, Mario. Childhood autism: translation and validation of the childhood autism rating scale for use in Brazil. Jornal de Pediatria (Rio de Janeiro), v. 84, n. 6, p. 487-494, 2008.

QUEIROZ, Lara. Leitura dialógica: efeitos no desenvolvimento de comportamento verbal em crianças com Transtorno do Espectro Autista (TEA). 2017. Dissertação (Mestrado em Ciências do Comportamento). Instituto de Psicologia da Universidade de Brasília, 2017.

RICCO LUCATO SIGOLO, Silvia. Diretividade materna e socialização de crianças com atraso de desenvolvimento. Paidéia, FFCLRP-USP, Ribeirão Preto, v. 10, n.19, p. 47-54, 2000.

SADALLA, Ana; LAROCCA, Priscila. Autoscopía: um procedimento de pesquisa e de formação. Educação e Pesquisa, v. 30, n. 3, p. 419-433, dez. 2004. ISSN 1678-4634.

SAINT-LAURENT, Lisa; GIASSON, Jocelyne.; COUTURE, Carole. Emergent literacy and intellectual disabilities. Journal of Early Intervention, v. 21, n. 3, p. 267-281, 1998.

SAMPAIO, Angelo, et al. Uma Introdução aos delineamentos experimentais de sujeito único. Interação em Psicologia, v.12, n.1, p. 151-164, São Paulo, 2008.

SCHOPLER, Eric; REICHLER, Robert; RENNER, Barbara. The childhood Autism Rating Scale (CARS). Los Angeles: Western Psychological Services, 1988

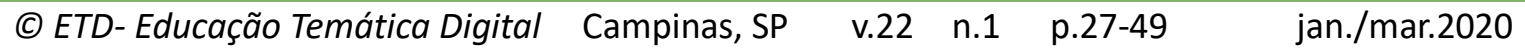


SOURESHJANI, Kamal; SAFIKHANI, Arezoo. The role of predictable stories in teaching english to persian EFL Children, Open Journal of Education, v. 1, n. 1, p.1-5, 2013.

TOWSON, et al. Dialogic reading in early childhood settings: a summary of the evidence base. Topics in Early Childhood Special Education, v. 37, n. 3, p. 132-146, 2017.

VAN KLEECK, Anne; VANDER WOUDE, Judith; HAMMETT Lisa. Fostering literal and inferential language skills in head start preschoolers with language impairment using scripted booksharing discussions. American Journal of Speech and Language Pathology, v. 15, p.85-95, 2006.

WALTER, Elizabeth et al. Augmenting caregiver responsiveness: an intervention proposal for youngsters with autism in Brazil. Early Childhood Education Journal, v. 44, n. 1, p. 39-49, 2016.

WALTER, Elizabeth. Os efeitos de um programa de compreensão da leitura oral dialógica por criança com autismo. 2017. 187f. Dissertação (Mestrado em Educação) - Centro de Educação, Universidade Federal do Rio Grande do Norte, Natal, 2017.

WHALON, Kelly, et al. the impact of reading to engage children with autism in language and learning (RECALL). Topics in Early Childhood Special Education, p.11-14, 2015.

WHALON, Kelly; HANLINE, Mary. F.; DAVIS, Jackie. Parent implementation of RECALL: a systematic case study. Education and Training in Autism and Developmental Disabilities, v. 51, n. 2, p. 211-220, 2016.

WHITEHURST, Grover, et al. Accelerating language development through picture-book reading. Developmental Psychology, v. 24, p.552- 558, 1988.

WRIGHT, Lisa; PRING, Tim; EBBELS, Susan. Effectiveness of vocabulary intervention for older children with (developmental) language disorder. International Journal of Language \& Communication Disorders, v. 53, n. 3, p. 480-494, 2018.

Revisão gramatical realizada por:

Sergio Rubens Alves Cavalvante.

E-mail: sergioalves26@hotmail.com 